\title{
Physical Characterization of Cottonseeds in Native Species (Gossypium spp.) From Mexico
}

\author{
C. Pérez-Mendoza ${ }^{1}$, M. R. Tovar-Gómez ${ }^{2}$, G. García de los $\operatorname{Santos}^{1}$ \& J. Suárez-Espinosa ${ }^{3}$ \\ ${ }^{1}$ Genetic Resources \& Productivity Program: Seed Production, Colegio de Postgraduados, Campus Montecillo, \\ Texcoco, State of Mexico, Mexico \\ 2 National Institute of Forestry, Agricultural \& Livestock Research, Valle of Mexico Experiment Station, \\ Texcoco, State of Mexico, Mexico \\ ${ }^{3}$ Socioeconomy, Statistics \& Information Program, Colegio de Postgraduados, Campus Montecillo, Texcoco, \\ State of Mexico, Mexico \\ Correspondence: M. R. Tovar-Gómez, Forage Program, National Institute of Forestry, Agricultural \& Livestock \\ Research (INIFAP), Valle of Mexico Experiment Station (CEVAMEX), Highway Los Reyes-Texcoco, Km. 13.5, \\ Coatlinchán, Texcoco, 56250, State of Mexico, Mexico. E-mail: tovar.rosario@inifap.gob.mx
}

Received: March 10, 2019

doi:10.5539/jas.v11n10p80

\author{
Accepted: May 5, 2019 Online Published: July 15, 2019 \\ URL: https://doi.org/10.5539/jas.v11n10p80
}

\begin{abstract}
The objective of this research was to do the physical characterization of cotton species (Gossypium spp.) based on the attributes of the seed. The experiment was performed at the Forage Biochemistry Laboratory of the Valle of Mexico Experiment Station, using seed of four cotton species (G. hirsutum, G. aridum, G. lobatum and G. shwendimanii). This research was carried out in two phases: in the first one, the weight of 1000 seeds and the hectolitre weight were determined. In the second one, seed dimensions were obtained by digital images and analysis process. The four cotton species were tested under a completely random experimental design. The data analysis was made by the variance analysis method, Tukey multiple comparison tests of means, principal components and cluster analysis. The results showed significant differences $(0.01 \%)$ in all the physical characters of the seeds. Based on the grouping analyzes, three groups with contrasting characteristics among the cotton species were identified, being G. hirsutum, the species that presented the highest value in the vector magnitude of the physical characters of the cottonseed. The area, width and weight of 1000 seeds were the main variables that explained $98.6 \%$ of the variability existing in the characteristics of the seed, so these physical attributes play an important role in the characterization of the Gossypium native species of Mexico.
\end{abstract}

Keywords: image analysis, seed dimensions, weight of 1000 seeds, hectolitre weight

\section{Introduction}

Cotton belongs to the Malvaceae family, the Gossypieae tribe and the Gossypium genus; there are currently 50 identified species, 45 diploids and tetraploids distributed in the continents of Asia, Africa, Australia and the Americas (Ulloa, 2014). This author also reports that in the western hemisphere, there are 13 wild diploid species of Gossypium, out of which eleven are native to Mexico (G. armourianum, G. lobatum, G. gossypioides, G. aridum, G. laxum, G. shwendimanii, G. thurberi, G. trilobum, G. davisonii, G. turneri and G. harknesii).

According to Curvelo (2000), out of the 50 species, four are grown worldwide due to their fiber with commercial value. These are originally from Peru (G. barbadense), Mexico (G. hirsutum), Asia (G. arboreum) and Africa (G. herbaceum) (Wendel \& Grover, 2015). The species G. hirsutum is the most widely grown and it covers approximately $95 \%$ of global production, G. barbadense, between 3 and $5 \%$, while G. herbaceum is important only in India and G. arboreum is grown locally in the driest areas of Africa and Asia (Lee \& Fang, 2015).

In order for the native Mexican cotton species to be preserved in germplasm banks, it is convenient to have the information necessary to help develop further studied, and within the important information, are the data of plant morphological, physiological and biochemical characteristics.

Núñez-Colín and Escobedo-López (2015) claim that characterizing a phytogenetic resource is determining the peculiar attributes of said resource so that it can be clearly told apart from any other. The distinctive characteristics of seeds, such as shape, size and color, play an important part in varietal identification 
(Smykalova et al., 2011), and the case of cottonseed is no exception. However, the conventional measurement of the variation in the characteristics of the seed has been difficult, usually with biases and systematic errors (Gyulai et al., 2015), apart from arduous and more time-consuming.

Computer-assisted digital morphometry quickly provides a powerful matrix of accurate and exact measurements of size, shape, texture and others in large seed populations (Gyulai et al., 2015). This technique is a quick, efficient and non-destructive method to determine the seed size profiles, as well as inexpensive (Mandal et al., 2012), making it a technological tool that can make the characterization of wild or planted cotton species more efficient.

Venora et al., (2009) report that the digital analysis of images has contributed in germplasm banks to organizing, conserving and identifying local bean breeds classified by seed size, shape, form, texture and color. This technique has also been used to characterize quinoa seeds (Medina et al., 2010), legumes (Firatligil-Durmus et al., 2010), maize, rice, soybean and pea (Mandal et al., 2012). These characteristics are especially interesting to design machinery that is used in the processing of seeds (Mandal et al., 2012). Due to this, the aim of the present study was to carry out the physical characterization of cotton species (Gossypium spp.) based on the attributes of the seed.

\section{Material and Methods}

\subsection{Collection the Species Under Study}

Four cotton species were selected (G. aridum, G. lobatum, G. shwendimanii and G. hirsutum), with distinctive characteristics to be incorporated in the conventional genetic breeding. In May of 2015, seeds of these cotton species were collected in the Mexican states of Colima (G. hirsutum), Nayarit (G. aridum) and Michoacán ( $G$. lobatum and G. shwendimanii).

The capsules collected for each cotton specie were placed in brown paper bags and transported to the Forage Biochemistry Laboratory of the Valle of Mexico Experiment Station (CEVAMEX-INIFAP) for conditioning.

The seeds were dried in the open, cleaned, and selected for their uniformity and cleanliness before being physically characterized. In the G. hirsutum seed, the only species with long fibers, these were separated from the seed by hand. Later, they were stored in brown paper bags at room temperature $\left(22^{\circ} \mathrm{C}\right)$ for one month.

The experiment was performed at the Forage Biochemistry Laboratory of the Valle de Mexico Experiment Station (CEVAMEX-INIFAP). The determination of the physical characteristics of different species was carried out in two phases. In the first, we determined the weight of 1000 seeds and the hectolitre weight; and in the second, we evaluated the dimensions of the seeds by the processing and digital analysis of images.

\subsection{Determination of Seed Physical}

Seed of the four Gossypium species were characterized regarding physical aspects using the following tests:

Weight of 1000 Seeds (W1000S): determined following the methodology recommended by the ISTA (ISTA, 2013) using eight repetitions of 100 seeds for each species of Gossypium.

Hectolitre Weight $(H W)$ : determined with the method ISO 7971-2:1995 (Determination of bulk density, called mass per hectolitre) in six seed repetitions.

\subsection{Digital Analysis of Images}

To process the image analysis, we used a CANON model Canonscan LIDE 100, a laptop and the software Image Tool 3.0. Five repetitions of 20 seeds were used for every species of Gossypium. The seeds were scanned and the images obtained were processed using the software mentioned. The variables registered were area, perimeter, seed length and width, elongation (length/width), factor-shape $\left(4 \pi\right.$ area/perimeter $\left.{ }^{2}\right)$, which is a quantitative measure of the degree of roundness (Linskens \& Jackson, 1992) and Feret diameter $(\sqrt{ } x(4 x$ area/ $\pi)$ ) (Wilcox et al., 2002).

\subsection{Statistical Analysis}

A one way analysis of variance were carried out for each of the variables, and in those in which statistical differences were found, a Tukey test was carried out $(0.05 \%)$. In addition, we carried out a principal components analysis, which helped identify the physical characteristics with the most influence to differentiate between cotton species by their seeds.

We also performed a cluster analysis using Euclidean distances calculated from standardized data. The construction of the dendogram derived from the Euclidian distances was carried out using the minimum Average variance. The height of the cut of the dendogram to define the number of cluster was established with the tests of 
cubic cluster criterion (CCC) and the statistic called Hollander's $\mathrm{T}^{2}$ pseudostatistic (Johnson \& Wichern, 2007). The groups with the cotton species and with discriminating variables were represented in a graph. The statistical analyses were carried out using the statistics software SAS (SAS, 2000).

\section{Results and Discussion}

Significant differences $(0.01 \%)$ were found between the cotton species studied for the variables of weight of 1000 seeds (W1000S) and hectolitre weight (HW). The coefficient of determination $\left(\mathrm{R}^{2}\right)$ for both variables was 0.99 , while the coefficient of variation (CV) for $\mathrm{W} 1000 \mathrm{~S}$ was $2.79 \%$, and for $\mathrm{HW}$, it was $1.86 \%$. According to the coefficient of variation registered for W1000S, there is a compliance with the ISTA (2013), since the result is accepted with a CV that does not exceed $6.0 \%$ for chaffy seeds and $4.0 \%$ for other types of seeds.

Regarding W1000S (Figure 1), the highest value was found in the species G. hirsutum, followed by G. lobatum, G. schwendimanii, while G. aridum was the species that registered the lowest W1000S. This variation registered in the W1000S may be due, mainly, to the size of the seed of each native species of cotton. In this regard, Thomson (1979) indicates that seed size is generally expressed as the weight of 1000 seeds, and is, to a certain extent, an inheritable trait, since the genetic variation presents itself more frequently in allogamous than autogamous plants. Likewise, Van Humbeeck and Oviedo de Cristaldo (2012) mention that W1000S is a varietal trait that has the least modifications due to the effect of the environment, and must therefore be taken into account for physical characterization studies on seeds.

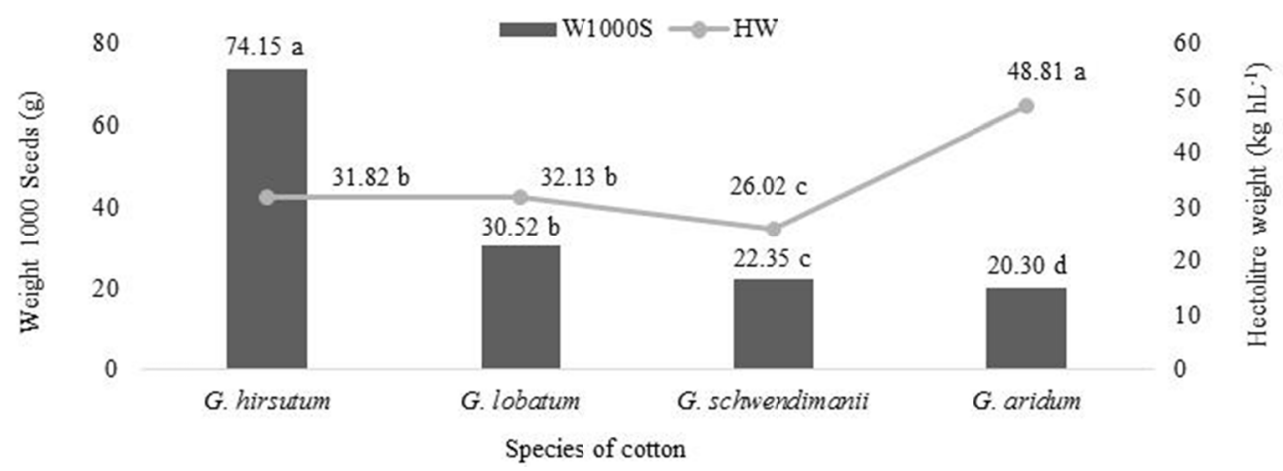

Figure 1. Behavior of the weight of 1000 seeds (W1000S) and hectolitre weight (HW) in cotton species. Means followed by the same letter do not differ by Tukey test at the $5 \%$ probability level

The species G. hirsutum and G. lobatum displayed no significant differences $(0.01 \%)$ in terms of hectolitre weight and were significantly lower than the species G. aridum, which recorded the highest value. In addition, the species G. schwendimanii presented the lowest HW value in comparison to the rest of the species (Figure 1).

On the other hand, there were significant differences $(0.01 \%)$ for all the variables of physical characterization of the seed of the cotton species, obtained through the image analysis (Table 1). The values of the coefficient of determination $\left(\mathrm{R}^{2}\right)$ ranged between 0.82 and 0.99 , which are similar to 1 , this indicates a good adjustment of the statistical model to discover the relation that exists between the study variables. The $\mathrm{CV}$ for the seven variables evaluated varied between 2.62 and $5.62 \%$, values that give high reliability values to the validity of these results. 
Table 1. Comparison of means for the variables of physical characterization evaluated in seeds of four cotton species native to Mexico

\begin{tabular}{lllll}
\hline \multirow{2}{*}{ Species } & \multicolumn{4}{c}{ Variables } \\
\cline { 2 - 5 } & Area $\left(\mathrm{mm}^{2}\right)$ & Perimeter $(\mathrm{mm})$ & Length $(\mathrm{mm})$ & Width $(\mathrm{mm})$ \\
\hline G. hirsutum & $40.60 \mathrm{a}^{t}$ & $26.53 \mathrm{c}$ & $9.37 \mathrm{c}$ & $5.50 \mathrm{a}$ \\
G. shwendimanii & $44.53 \mathrm{a}$ & $55.10 \mathrm{a}$ & $13.21 \mathrm{a}$ & $5.03 \mathrm{ab}$ \\
G. lobatum & $40.42 \mathrm{a}$ & $31.84 \mathrm{~b}$ & $11.86 \mathrm{~b}$ & $4.36 \mathrm{c}$ \\
G. aridum & $30.33 \mathrm{~b}$ & $25.48 \mathrm{c}$ & $8.63 \mathrm{c}$ & $4.73 \mathrm{bc}$ \\
Significant & $*$ & $*$ & $*$ & $*$ \\
$\mathrm{R}^{2}$ & 0.91 & 0.99 & 0.96 & 0.82 \\
CV & 5.62 & 5.31 & 4.80 & 5.36 \\
Mean & 38.97 & 34.74 & 10.77 & 4.90 \\
HMSD (Tukey, 0.05) & 4.11 & 4.20 & 0.97 & 0.49
\end{tabular}

Note. $\mathrm{R}^{2}$ : Coefficient of determination; CV: Coefficient of variation; *: Significant at the $0.01 \%$. HMSD: Honest minimum significant difference; ${ }^{t}$ Means with same letters are not statistically different by Tukey test at the $5 \%$ probability level.

Regarding the variable of seed area, the averages of G. hirsutum, G. shwendimanii and G. lobatum displayed no significant differences $(0.01 \%)$ between them, although there was $(0.01 \%)$ regarding the species G. aridum, which recorded the lowest value. In this context, Arapa and Padrón (2014) have reported that a physical characteristic such as seed area is of particular interest to the seed industry, especially for the design of sieves and seed processing chambers.

Regarding the perimeter of the seed, there were no significant differences between G. hirsutum and G. aridum, although there were significant differences $(0.01 \%)$ between these species and G. lobatum and G. shwendimanii, the latter being the species that registered the highest value in this variable. The data obtained for the seed perimeter are crucial in the seed industry, since, using the information determined in this parameter, sieves or specific machinery could be designed, highly useful to the conditioning and benefit of seeds.

Regarding the length of the seed, we observed that the species G. shwendimanii and G. lobatum were significantly different $(0.01 \%)$ between them, but also to G. hirsutum and G. aridum; however, the two latter presented lower and similar values $(0.01 \%)$. Regarding seed width, the highest values were for G. hirsutum and G. shwendimanii, which presented no significant differences $(0.01 \%)$ between them, yet they presented differences with G. lobatum $(0.01 \%)$. Seed width for G. aridum was similar to G. lobatum. In this regard, Sunanda and Kakatkar (2013), as well as Medina et al. (2010), report that seed length and width indicate size and may me correlated to aspects of vigor and germination of seeds.

On the other hand, significant differences were found $(0.01 \%)$ for seed elongation among the species evaluated (Figure 2), with G. shwendimanii and G. lobatum having similar values $(0.01 \%)$, yet different to G. hirsutum and G. aridum, which showed no significant differences between them $(0.01 \%)$. It is important to point out that the values obtained for this variable are relevant for the design of machinery for harvesting, transportation, cleaning, separation, packaging and processing of seeds (Mandal et al., 2012).

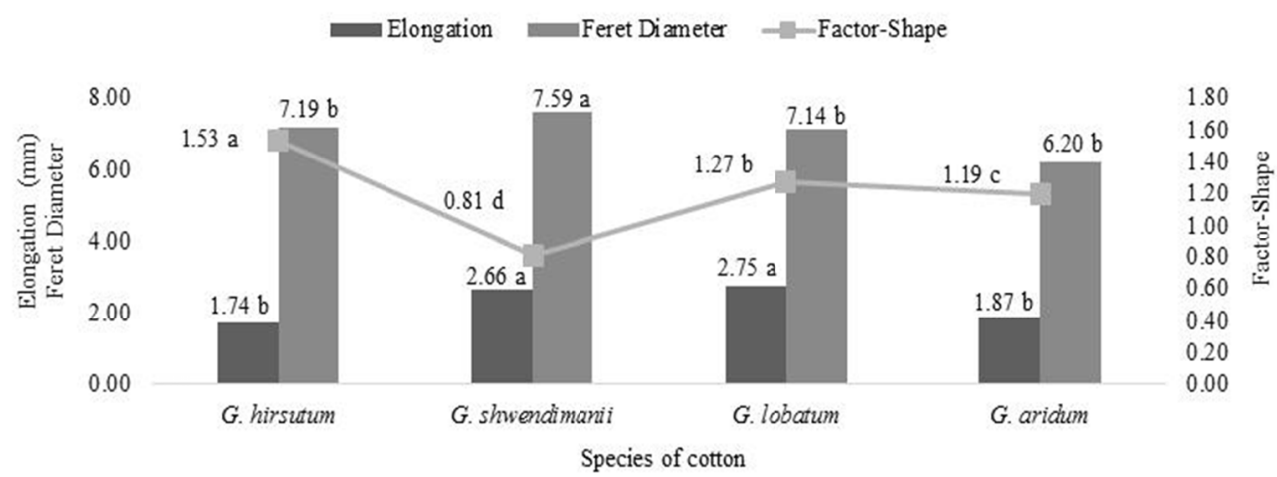

Figure 2. Behavior of Elongation, Feret Diameter and Factor-Shape, determined by the digital analysis of images of cottonseeds. Means followed by the same letter do not differ by Tukey test at the $5 \%$ probability level 
When analyzing the Feret diameter $\left(\mathrm{d}_{\mathrm{F}}\right)$, which is the average value of the distance between pairs of parallel lines in a tangent to the projected perimeter of each seed, differences were observed between species $(0.01 \%)$ with $G$. shwendimanii having the highest value, and the rest displayed similar values. Regarding the factor-shape index, all cotton species were statistically different $(0.01 \%)$, with $G$. shwendimanii having the lowest value. Puecher et al. (1996) point out that, in many species, the shape of the seed has been used to explain differences between genotypes and for the design of planting and benefit equipment.

In order to identify the traits with the greatest influence in the differentiation of the cotton species, principal components and cluster analyses were carried out. Before the analysis, the data were analyzed for collinearity and the variables of elongation, the Feret diameter and the factor-shape were eliminated due to their collinearity with perimeter, length and width of seed.

Based on the results obtained, three components described $98.6 \%$ of the total variance (Table 2). The first principal component (PC1) explains $58.9 \%$ of the variance and the main variable that describes this variation in the area of the Gossypium seed. The second component (PC2) explains $30.2 \%$ and the variables related to this component are the weight of 1000 seeds and the width of the seeds of the different cotton species. The third principal component (PC3) explains $9.5 \%$ of the total variability and the main variable is the width of the cottonseed. In this regard, Kapadia et al., (2017) mention that the variables of size, shape, texture and color of the seed helped improve the organization, classification and improvement of the wild species that are stored in the germplasm banks.

Table 2. Proportion of absolute and accumulated variance of the first three main components of four cottonseeds of species (Gossypium spp.) native to Mexico

\begin{tabular}{lllllllll}
\hline $\begin{array}{l}\text { Principal } \\
\text { Component }\end{array}$ & $\begin{array}{l}\text { Weight of } \\
1000 \text { seeds }(\mathrm{g})\end{array}$ & $\begin{array}{l}\text { Hectolitre } \\
\text { weight }\left(\mathrm{kg} \mathrm{hL}^{-1}\right)\end{array}$ & $\begin{array}{l}\text { Area } \\
\left(\mathrm{mm}^{2}\right)\end{array}$ & $\begin{array}{l}\text { Perimeter } \\
(\mathrm{mm})\end{array}$ & $\begin{array}{l}\text { Length } \\
(\mathrm{mm})\end{array}$ & $\begin{array}{l}\text { Width } \\
(\mathrm{mm})\end{array}$ & $\begin{array}{l}\text { Explained } \\
\text { variance }(\%)\end{array}$ & $\begin{array}{l}\text { Accumulated } \\
\text { variance }(\%)\end{array}$ \\
\hline 1 & -0.005 & -0.494 & 0.509 & 0.469 & 0.481 & 0.212 & 58.9 & 58.9 \\
2 & 0.712 & -0.154 & 0.133 & -0.243 & -0.298 & 0.550 & 30.2 & 89.1 \\
3 & -0.362 & 0.348 & -0.194 & 0.421 & -0164 & 0.710 & 9.5 & 98.6 \\
\hline
\end{tabular}

On the other hand, for the cluster analysis using the Average's minimum variance method and Euclidian distances squared (Johnson, 2000), we included the six variables selected. Figure 3 represents the values of the cubic cluster criteria and of Hollander's $\mathrm{T}^{2}$ pseudostatistics (Johnson, 2000). These statistical tools were used to define that three was the appropriate number of clusters of the four species of cotton.
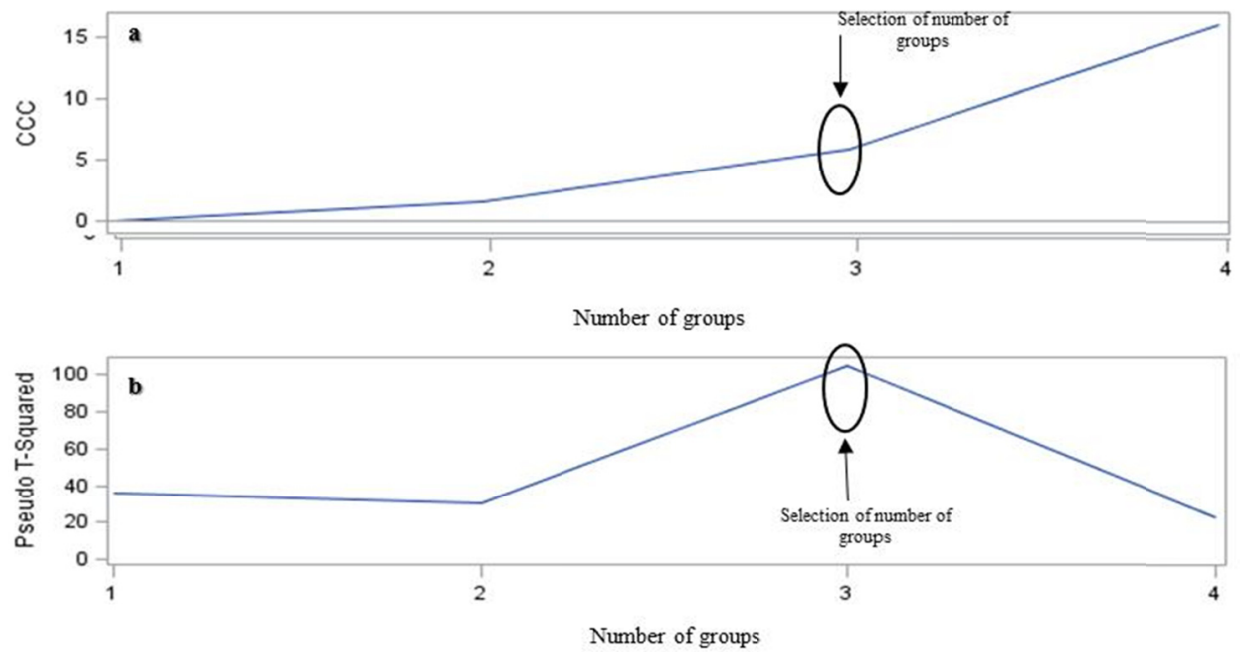

Figure 3. Definition of the number of groups formed according to the cubic cluster criterion (3a) and Hollander's $\mathrm{T}^{2}$ pseudostatistic (3b)

Based on the comparison of average vectors with Bonferroni's adjustment (Table 3) and in the cluster analysis (Figure 4), it was determined that group I registered the greatest vector magnitude (94), followed by group II 
(80), and the lowest value was found in group III (67), presenting significant differences between them (0.05\%). Group I was formed by the tetraploid species G. hirsutum $\left(\mathrm{AD}_{1}\right)$, which had characteristically high values for W1000S and seed width. Gotmare et al., (2018) mention some characteristics of G. hirsutum, which is an annual shrub with wide to very narrow leaves, with nectaries; capsules that can be round, oval-shaped or elongated, large, and containing three to five locules. These authors also report that the fiber of G. hirsutum can be white, brown or green and seeds are approximately $10 \mathrm{~mm}$ long by $4 \mathrm{~mm}$ in width.

Group II is formed by the diploid species G. shwendimanii $\left(\mathrm{D}_{11}\right)$, which has a greater area, perimeter, and seed length. Ulloa (2014) reports this species as endemic of the state of Michoacán, and is a bush with characteristically lanceolate and long, with small, light-brown capsules, with three locules; seeds are, on average $10.0 \mathrm{~mm}$ long and $2.5 \mathrm{~mm}$ wide.

Table 3. Vectors of means with the Bonferroni adjustment and magnitude of the vector of the physical characteristics in cottonseeds (Gossypium spp.)

\begin{tabular}{lllllllll}
\hline Group & Literal & W1000S $(\mathrm{g})$ & $\begin{array}{l}\text { Hectolitre weight } \\
\left(\mathrm{kg} \mathrm{hL}^{-1}\right)\end{array}$ & Area $(\mathrm{mm})$ & $\begin{array}{l}\text { Perimeter } \\
(\mathrm{mm})\end{array}$ & Length $(\mathrm{mm})$ & width (mm) & $\begin{array}{l}\text { Magnitude } \\
\text { vector }\end{array}$ \\
\hline I & $\mathrm{a}$ & 74.15 & 32.82 & 40.60 & 25.53 & 9.37 & 5.50 & 94 \\
II & $\mathrm{b}$ & 22.35 & 26.02 & 44.53 & 55.10 & 13.21 & 5.03 & 80 \\
III & $\mathrm{c}$ & 25.41 & 40.47 & 35.38 & 28.66 & 10.25 & 2.55 & 67 \\
\hline
\end{tabular}

Group III is composed of the diploid species G. aridum $\left(\mathrm{D}_{4}\right)$ and G. lobatum $\left(\mathrm{D}_{7}\right)$ and its main characteristic is having a greater hectolitre weight seed. Ulloa (2014) mentions that G. aridum is distributed between northern Sinaloa and southern Oaxaca, and is a bush with characteristically few branches, small capsules with four locules, and a dark brown color; seeds measure, on average $7.3 \times 1.7 \mathrm{~mm}$. The species G. lobatum is endemic to the state of Michoacán, it is arborescent, and the capsule is light brown in color with three locules and seeds measuring an average of $10.0 \times 1.8 \mathrm{~mm}$.

It is important to point out that G. aridum has genes that give it resistance to cotton rust (Puccinia cacbata A\&H) and late drying (Verticillium dahliae K.), whereas G. lobatum, presents characteristics and it is very important that it can be incorporated character in the cultivated varieties to avoid the use of defoliants and thus have better quality of the fiber, free of leaf residues (Palomo, 1996).

The results obtained in the present study show that there is a wide genetic variability in the physical attributes of cottonseeds, which is useful to tell species apart and to achieve a better characterization, which is very important in the genetic breeding programs for the creation of new conventional cotton varieties in Mexico.

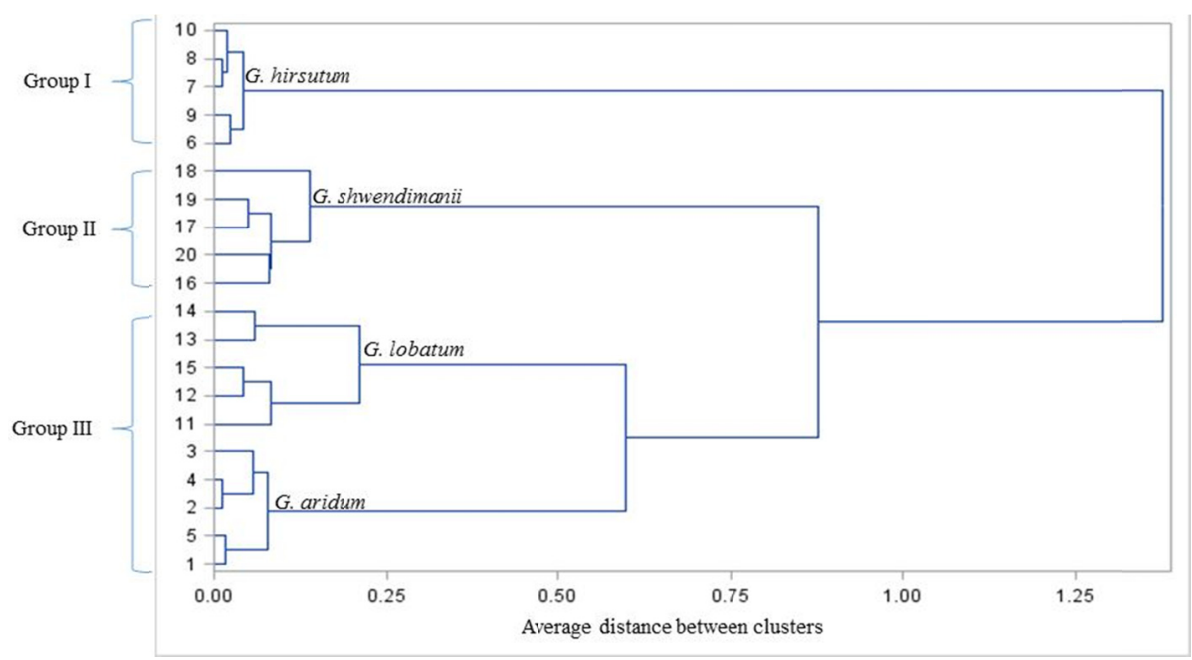

Figure 4. Dendrogram of cotton species, created using Euclidian distances 


\section{Conclusions}

Three groups with contrasting characteristics between cotton species were identified, with G. hirsutum having the highest value in the magnitude of the vector of the physical characteristics of cottonseeds. The area, width and weight of 1000 seeds were the main parameters that accounted for $98.6 \%$ of the variability in the characteristics of seeds, hence the reason for these physical attributes playing an important role in the characterization of Gossypium species native to Mexico.

\section{Acknowledgements}

The main author would like to thank the National Science and Technology Council (CONACyT) for the scholarship awarded for her graduate studied. The authors would like to thank the INIFAP for the funds granted and directing the investigation, to the Colegio de Postgraduados for the economic aid to the present study, and to Dr. Martha Elena Pedraza Santos for her help in recollection native cottonseeds of Michoacán.

\section{References}

Arapa, C. P., \& Padrón, A. C. (2014). Determination of physical characteristics of quinoa (Chenopodium quinoa Willd.) seeds by digital processing of images. Rev. Venez. Cienc. Tecnol. Aliment., 5(2), 148-165.

Curvelo, F. E. (2000). Distribution, collection, use and preservation of wild cotton species in Brazil (p. 24). Ministerio da Agricultura, Pecuária e Abastecimiento. Retrieved from https://ainfo.cnptia.embrapa.br/ digital/bitstream/CNPA/14839/1/DOC78.pdf

Firatligil-Durmus, E., Šarka, E., Bubnik, Z. K., Schejbal, M., \& Kadlec, P. (2010). Size properties of legume seeds of different varieties using image analysis. J. Food Engr., 99, 445-451. https://doi.org/10.1016/ j.jfoodeng.2009.08.005

Gotmare, V., Singh, P., \& Tule, B. N. (2018). Wild and cultivated species of cotton. Central Institute for Cotton Research Nagpur. Retrieved from http://www.cicr.org.in/pdf/wild_species\%20.pdf

Gyulai, G., Rovner, I., Vinogradov, S., Kerti, B., Emödi, A., Csákvárf, E., ... Gyulai, F. (2015). Digital seed morphometry of dioecious wild and crop plants development and usefulness of the seed diversity index. Seed Sci. \& Technol., 43, 492-506. https://doi.org/10.15258/sst.2015.43.3.15

ISO (International Organization for Standardization). (1995). Determination of bulk density, called mass per hectoliter (Part 2: Routine method). ISO 7971-2. Retrieved from https://www.iso.org/standard/20818.html

ISTA (International Seed Testing Association). (2013). International rules for seed testing (p. 243). Seed Sci. \& Technol. Bassersdorf, Switzerland.

Johnson, R. A., \& Wichern, D. W. (2007). Applied Multivariate Statistical Analysis (p. 773). Pearson Education, Inc. Pearson Prentice Hall Pearson Education, Inc. Upper Saddle River, Nueva Jersey, United States of America.

Kapadia, V. N., Sasidharan, N., \& Patil, K. (2017). Seed image analysis and its application in seed science research. Adv. Biotechy. \& Microbiol., 7(2), 1-3. https://doi.org/10.19080/AIBM.2017.07.555709

Lee, J. A., \& Fang, D. D. (2015). Cotton as a world crop: Origin, history, and current status. In D. D. Fang \& R. G. Percy (Eds.), Cotton (pp. 1-24). American Society of Agronomy, Inc. Crop Science Society of America, Inc. Soil Science Society of America, Inc. United States. https://doi.org/10.2134/agronmonogr57.2013.0019

Linskens N. F., \& Jackson, J. F. (1992). Seed analysis (p. 380). Springer-Verlag, Germany. https://doi.org/ 10.1007/978-3-662-01639-8

Mandal, S., Roy, S., \& Tanna, H. (2012). A low-cost image analysis technique for seed size determinations. Curr. Sci., 103(12), 1401-1403.

Medina, W., Skurtys, O., \& Aguilera, M. (2010). Study on image analysis application for identification Quinoa seeds (Chenopodium quinoa Willd) geographical provenance. Food Sci. \& Tech., 43, 238-246. https://doi.org/10.1016/j.lwt.2009.07.010

Núñez-Colín, C. A., \& Escobedo-López, D. (2015). Characterization of plant germplasm: the cornerstone in the study of plant genetic resources. Acta Agrícola y Pecuaria, 1(1), 1-6.

Palomo-Gil, A. (1996). Distribution, collection and use of wild cotton species in Mexico. Ciencia, 47(4), 359-369.

Puecher, D. I., Ibañez, M. A., \& Di Renzo, A. (1996). Classification and diversity values of seventeen cultivars of Eragrostis curvula. Seed Sci. \& Technol., 24, 139-149. 
SAS Institute Inc. (2000). SAS/STAT guide for personal computers (9.0 version, p. 5121). North Carolina, United States of America.

Smykalova, I., Grillo, O., Bjelkova, M., Hybl, M., \& Venora, G. (2011). Morpho-colorimetric traits of Pisum seeds measured by an image analysis system. Seed Sci. \& Tech., 39, 612-626. https://doi.org/10.15258/ sst.2011.39.3.08

Sunanda, V. N., \& Kakatkar, M. N. (2013). Seed property measurement with image analysis. Int. J. Scic. \& Engr. Res., 4(7), 18-22.

Thomson, J. R. (1979). An Introduction to Seed Technology (p. 301). ACRIBIA, Spain.

Ulloa, M. (2014). The diploid D genome cottons (Gossypium spp.) of the New World. World Cotton Germplasm Resources. In I. Abdurakhmonov (Ed.), IntechOpen (pp. 203-229). United Kingdom. https://doi.org/ $10.5772 / 58387$

Van Humbeeck, A. M. A., \& Oviedo de Cristaldo, R. M. (2012). Plant population and their effect on the vegetative development and yield of sesame (Sesamum indicum L.) variety Escoba. Investig. Agrar., 14(1), 25-30.

Venora, G., Grillo, O., RavallI, C., \& Cremonini, R. (2009). Identification of Italian landraces of bean (Phaseolus vulgaris L.) using an image analysis system. Sci. Hort., 121(4), 410-418. https://doi.org/ 10.1016/j.scienta.2009.03.014

Wendel, J. F., \& Grover, C. E. (2015). Taxonomy and evolution of the cotton genus, Gossypium. In D. D. Fang, \& R. G. Percy (Eds.), Cotton (pp. 25-44). American Society of Agronomy, Inc. Crop Science Society of America, Inc. Soil Science Society of America, Inc. United States. https://doi.org/10.2134/ agronmonogr 57.2013 .0020

Wilcox, C. D., Dove, S. B., McDavid, W. W. D., \& Greer, D. B. (2002). UTHSCSA. Image Tool Version 3.0 (p. 56). University of Texas Health Science Center, San Antonio, Texas, United States.

\section{Copyrights}

Copyright for this article is retained by the author(s), with first publication rights granted to the journal.

This is an open-access article distributed under the terms and conditions of the Creative Commons Attribution license (http://creativecommons.org/licenses/by/4.0/). 